\title{
Más allá de la modernización y de la autenticidad. Un proyecto de metafilosofía práctica latinoamericana
}

\section{Guillermo Hurtado}

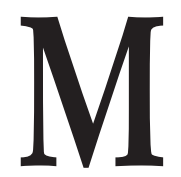

\section{etafilosofía práctica latinoamericana}

A pesar de lo mucho que se ha escrito sobre la cuestión de la filosofía en América Latina todavía es preciso reflexionar sobre estos asuntos. Pero lo que no podemos seguir haciendo es continuar repitiendo lo mismo que venimos escuchando desde hace décadas. Es tiempo ya de adoptar nuevos modelos explicativos, de hacer una relectura de la historia de la filosofía en América Latina, de localizar el fondo genuino de sus problemas y, sobre todo, de ofrecer nuevas soluciones. El propósito de este ensayo es sentar las bases para dicha tarea.

Antes de considerar el problema de la filosofía en América Latina es conveniente decir algo acerca de la naturaleza del problema.

Hay quienes sostienen que todo esto es un enorme disparate, que no hay un problema estrictamente filosófico acerca de la filosofía en América Latina. Lo que hay, nos dirían, son cuestiones sobre la historia de la filosofía en nuestros países, pero nada más. Por otra parte, hay quienes afirman que el problema sobre la filosofía en América Latina no es tan sólo histórico, sino que es un problema filosófico como cualquier otro; para algunos es un problema ontológico, para otros epistemológico, para otros ético y, para otros más, hay problemas de todos estos tipos. En mi opinión ambas respuestas son incorrectas.

Hay un problema filosófico acerca de la filosofía en América Latina pero no es un problema filosófico como cualquier otro, es decir, no es un problema ontológico, ni epistemológico, ni ético - aunque pienso que está conectado con problemas de esta naturaleza y, de manera esencial, con cuestiones históricas.

El problema de la filosofía en América Latina es, en mi opinión, un problema metafilosófico. Más aún, pienso que uno de los problemas de nuestra filosofía ha sido el no reconocer lo anterior. 
Para entender qué tipo de problema metafilosófico es el que nos ocupa, conviene hacer antes algunas precisiones sobre la metafilosofía.

Así como ahora se distingue entre la ética y la ética práctica, me parece que podemos hablar de una metafilosofía teórica y una metafilosofía práctica.

La metafilosofía teórica es la reflexión filosófica -creo que no es preciso llamarla "disciplina" - acerca de la naturaleza, forma y alcances de la filosofía. Ejemplos de metafilosofía teórica son la caracterización de la metafísica que hace Aristóteles, la crítica wittgensteniana de la filosofía y la filosofía de la filosofía de José Gaos.

La metafilosofía práctica, por otra parte, es la reflexión -también filosófica, aunque, como veremos, con características sui generis- sobre las condiciones y los problemas de la práctica concreta de la filosofía en un lugar y momento dados. Ejemplos de metafilosofía práctica son la crítica de Sócrates a los sofistas atenienses o la de Marx a la filosofia idealista alemana. Abundan los practicantes de la metafilosofía práctica entre nosotros. En España han destacado Marcelino Menéndez Pelayo, Miguel de Unamuno y José Ortega y Gasset. En Iberoamérica la lista es más larga e incluiría a Antonio Caso, Francisco Romero, Rizieri Frondisi, Francisco Miró Quesada, Augusto Salazar Bondy, Leopoldo Zea, Luis Villoro y Arturo Andrés Roig, entre otros.

Si bien la metafilosofía práctica considera las prácticas concretas de la filosofía en un contexto histórico, social, político e incluso económico, no debe confundirse con la sociología de la filosofía. La metafilosofía práctica es, en parte, una disciplina empírica, ya que se ocupa de hechos concretos, pero tiene una parte no-empírica, estrictamente filosófica, que es lo que he llamado metafilosofía teórica. Las descripciones, explicaciones, juicios y propuestas de la metafilosofía práctica dependen de la concepción de la filosofía que se adopta desde un punto de vista meramente teórico. Por ejemplo, la evaluación que ha hecho la metafilosofía práctica marxista de la filosofía latinoamericana depende de la metafilosofía teórica marxista y, por tanto, se distingue de la que ha hecho la metafilosofía práctica analítica de la misma filosofía latinoamericana. En ambos casos los datos empíricos son los mismos, lo que cambia es el marco teórico de las dos metafilosofías prácticas. ${ }^{1}$

${ }^{1}$ Así como las reflexiones ético-prácticas son relevantes para la formulación de códigos de conducta y de legislación, las reflexiones metafilosófico-prácticas sobre la manera en la que se practica la filosofía en una comunidad o institución son relevantes para la planeación y la administración de algunos de los elementos que conforman la práctica filosófica en dicho sitio. No ignoro que cuando el Estado o la Iglesia han intentado planear la filosofía, lo que han hecho, casi siempre, ha sido truncar la libertad requerida para hacer filosofía verdadera. Pero yo no me refiero a esta planeación totalitaria o intolerante. No pueden dejar de planearse algunos de los elementos que conforman la práctica filosófica. El ideal, en estos casos, es que la planeación esté 
Una de las características más peculiares, quizá la más singular, de la filosofía latinoamericana es la importancia que en ella han tenido los estudios metafilosóficos y, en especial, los de metafilosofía práctica. Estos estudios tienen algunos elementos en común que los distinguen de otros trabajos de metafilosofía práctica realizados en otros lados. Por ello, podemos hablar con justicia de una metafilosofía práctica latinoamericana. ${ }^{2}$

No confundamos a la metafilosofía práctica latinoamericana con lo que se conoce como filosofía latinoamericana, ni con la llamada filosofía de la liberación. Ni los latinoamericanistas ni los liberacionistas son los únicos que han practicado o practican hoy en día la metafilosofía práctica latinoamericana. La metafilosofía práctica latinoamericana -y esta es, me parece, la utilidad de este membrete- es una reflexión distinta por su propia naturaleza de las filosofías latinoamericana y de la liberación, ya que es una reflexión más general que puede tomar como objeto de estudio a las filosofías latinoamericana y de la liberación mismas e incluso criticarlas.

Sin embargo, existe mucha confusión en este respecto, producida, en buena medida, por las actitudes de confrontación y descalificación que ha habido entre los filósofos latinoamericanistas o liberacionistas y el resto de sus colegas. Estas actitudes - que se dan en los dos bandos- han producido el prejui-

basada en una reflexión metafilosófica práctica, seria y cuidadosa. Por dar un ejemplo, en todos lados se planean -como su nombre lo indica- los planes de estudio de las carreras de filosofía. En América Latina hemos tenido ejemplos de propuestas de planes de estudio basadas en una metafilosofía atenta a la realidad de nuestros países. Uno de ellos es el célebre texto de Juan Bautista Alberdi, "Ideas para un curso de filosofía contemporánea". Otro, más reciente, es el proyecto para un plan de estudios que propuso José Gaos en su libro La filosofía en la Universidad (México, UNAM, 1954). Pero hay que subrayar que la metafilosofía práctica no depende de que haya elementos de la práctica filosófica que deban planearse o administrarse. La metafilosofía práctica es, en última instancia, una reflexión crítica sobre la práctica filosófica en una comunidad. Si de esta reflexión surge alguna buena propuesta para la preservación o el cambio de algunos de los elementos que constituyen dicha práctica, tanto mejor, pero no es una condición necesaria para ella.

${ }^{2}$ No es este el lugar para examinar los elementos comunes que pueden hallarse en las obras de metafilosofía práctica latinoamericana. Pero podríamos mencionar que uno de ellos es la idea de que la filosofía en América Latina debe tener un impacto positivo en la vida cultural, social y política de nuestros pueblos. Hemos querido que la filosofía que profesamos no sólo sea acorde con los cambios que efectuamos en nuestros países, sino que promueva dichos cambios. En este punto han estado de acuerdo casi todos. Los positivistas del siglo XIX querían que su filosofía sirviera para borrar el lastre de la escolástica e impulsara el progreso de nuestros países. Los marxistas querían -al menos algunos de ellos- que la propagación de su filosofía impulsara la revolución. Y los filósofos de la liberación han querido que su filosofía no sólo se ocupe de los pobres, sino que luche en su favor. 
cio de que sólo los latinoamericanistas o los liberacionistas pueden hacer lo que he llamado metafilosofía práctica latinoamericana.

Una vez que hemos caracterizado lo que he llamado metafilosofía práctica latinoamericana, mi propósito en lo que resta de este ensayo es identificar los que, en mi opinión, son los problemas principales a los que debe enfrentarse. Para ello, es preciso que ofrezca un panorama muy a vuelo de pájaro de las tendencias principales de la filosofía en América Latina.

A partir de la ruptura con la filosofía escolástica en el siglo XIX, hemos cultivado dos modelos distintos de filosofía que están basados en dos modelos de metafilosofía práctica diferentes. A uno lo llamaré el modelo modernizador y al otro, por falta de mejor nombre, el modelo de la autenticidad. ${ }^{3}$

\section{El modelo modernizador}

El fenómeno de la modernización de nuestra filosofía se remonta al siglo XVIII, cuando en España, Portugal y sus colonias americanas se da un movimiento de apertura a la filosofía y la ciencia modernas. Esta primera modernización no rompió del todo con la tradición escolástica, sino que intentó convivir con ella de manera ecléctica. Más adelante recibimos las influencias, esta vez más disruptivas, de la Ilustración, el liberalismo y el romanticismo. Estos movimientos dejaron una honda huella en nuestra cultura, más no así en nuestra filosofía. Es hasta el tercer cuarto del siglo XIX, con el positivismo, que inicia una serie de lo que podemos llamar movimientos modernizadores de nuestra filosofía. Si bien hay diferencias importantes en cada país, podemos decir que, a partir de entonces, hemos tenido al menos cuatro movimientos modernizadores.

${ }^{3}$ La distinción que propongo entre el modelo modernizador y el de la autenticidad no debe confundirse con la que hacen la mayoría de los estudiosos de nuestra filosofía entre el modelo universalista y el particularista. Si bien algunos sucesos de nuestra filosofía pueden verse como un enfrentamiento entre una postura universalista y una particularista, esta distinción no sirve para entender otros sucesos importantes de nuestra filosofía, en especial, los más recientes. Algunos universalistas son más limitados en su adopción acrítica de la filosofía practicada en alguna universidad europea que muchos de los supuestos particularistas. Y algunos de los supuestos particularistas conciben su trabajo filosófico de una manera más universalista que la de sus supuestos oponentes. La distinción que yo propongo entre el modelo modernizador y el de la autenticidad no tiene estos problemas, ya que lo que los distingue no es una concepción general acerca de la universalidad que debería tener la filosofía latinoamericana, sino una idea acerca del tipo de problemas al que debería enfrentarse el filósofo latinoamericano. 
1. En la segunda mitad del siglo XIX compartimos una modernización positivista. El positivismo latinoamericano se presenta como la filosofía que requiere el progreso social y material de nuestros pueblos y tiene, por lo tanto, una carga ideológica, pero también abre, por primera vez, las ventanas de par en par a la filosofía europea. Este movimiento acaba a principios del siglo $\mathrm{xx}$ con la generación de maestros fundadores en la que destacan Antonio Caso, Alejandro Korn, Alejandro Deustua y Carlos Vaz Ferreira.

2. Después del declive del positivismo inicia una gran modernización de origen germánico que propagó diversas corrientes como el neokantismo, el historicismo, la axiología, la fenomenología y el existencialismo. En esto tuvo mucho que ver la influencia de Ortega y de la Revista de Occidente. Éste es también el periodo en que los discípulos de los fundadores trabajan para lograr lo que Romero llamó la normalización de la filosofía latinoamericana. En México esta modernización empieza a mostrar signos de debilitamiento hacia 1960, pero en otros lugares se prolonga hasta nuestros días. Entre las figuras de este movimiento destacan José Gaos, Francisco Romero y Ernesto Mayz Vallenilla.

3. También en la primera mitad del siglo XX inicia una modernización marxista, con influencias y orientaciones muy diversas, que van desde Marx y Gramsci hasta Bloch y Althusser. Este movimiento - que como el positivista se propuso influir en la realidad social- se ocupó de un abanico muy amplio de problemas filosóficos que van desde la lógica hasta la estética. La filosofía marxista fue muy golpeada en los años setentas por las dictaduras militares, y ahora son pocos quienes la cultivan desde la caída del muro de Berlín. Destacan en ella Carlos Astrada, Eli de Gortari, Adolfo Sánchez Vázquez y João Cruz Costa.

4. Por último, en la segunda mitad del siglo xx, hacia finales de los años cincuentas, comienza una modernización analítica. En Argentina destacan, entre los fundadores, Mario Bunge, Gregorio Klimosky y Tomás Moro Simpson. En México, Alejandro Rossi, Fernando Salmerón y Luis Villoro. Los analíticos dan otro impulso a la tarea de normalización de la filosofía latinoamericana, poniendo énfasis en el dominio de técnicas, como la lógica, el conocimiento de las ciencias, como lo habían intentado antes los positivistas, y en el rigor del trabajo filosófico. Este movimiento sigue activo, aunque ha bajado su tono modernizador.

Como he dicho, este esquema es muy aproximado. ${ }^{4}$ En todo caso me parece que nuestras modernizaciones han tenido ciertas características comunes. A continuación señalaré tres de ellas.

\footnotetext{
${ }^{4}$ Se podría decir que a principios del siglo xx el bergsonismo tuvo tal importancia a nivel continental que debería describirse como una corriente modernizadora más. También podríamos señalar varias diferencias significativas entre cada país. En algunos
} 
La primera es que han sido proyectos importados por un grupo modernizador inicialmente pequeño. Las modernizaciones han buscado imponer nuevos modelos externos para sustituirlos por viejos modelos en uso interno -aunque estos últimos también hayan sido, en su origen, importados. El que estos proyectos hayan sido foráneos y, por tanto, novedosos, tiene como consecuencia que, en un primer momento, la modernización tenga que limitarse a ser un mero aprendizaje de las nuevas doctrina y técnicas. Esto pone a los filósofos latinoamericanos en una relación de alumno/maestro con los filósofos extranjeros. Uno de los problemas de nuestras modernizaciones es que rara vez han pasado de ese primer momento, el periodo de aprendizaje se ha prolongado demasiado sin que se pase a uno de creación original. Hay brillantes excepciones, todos las conocemos, pero son pocas. En las obras de la mayoría de nuestros modernizadores sólo se estudian y se discuten las obras de filósofos extranjeros reconocidos como autoridades. Pero los filósofos extranjeros, incluso los que visitan nuestros países para dar conferencias, rara vez nos citan en sus obras. En consecuencia, no hay un diálogo genuino entre los modernizadores latinoamericanos y los filósofos extranjeros que ellos emulan. No existe diálogo cuando unos hablan y otros sólo toman notas. ${ }^{5}$ Por lo mismo, los modernizadores latinoamericanos pocas veces forman parte en verdad de las comunidades filosóficas extranjeras a las que ellos creen pertenecer o desearían hacerlo. Y parece que sólo pueden hacerlo si escriben en otro idioma que no sea el español o el portugués. Pero tener que dejar a un lado nuestro propio idioma para poder ser escuchado es, por muchas razones, lamentable. ${ }^{6}$ Por otra parte, los modernizadores latinoamericanos dialo-

lugares, por ejemplo en Brasil, la influencia de la filosofía francesa ha sido más pertinaz y, en otros, sería exagerado hablar de una modernización analítica. Por otra parte, en años recientes hemos recibido la influencia del estructuralismo, la teoría crítica, la hermenéutica filosófica y el pensamiento posmoderno, pero me parece que ninguna de estas corrientes se ha constituido todavía en un movimiento modernizador como los ya mencionados.

${ }^{5}$ No está de más aclarar que no afirmo que no debamos conceder a ningún extranjero el papel de maestro. Por el contrario, creo que siempre debemos reconocer y respetar el valor del trabajo filosófico. Lo que yo diría es que este principio también debemos hacerlo válido para nosotros. Es decir, debemos reconocer a nuestros maestros y esperar que su trabajo sea reconocido aquí y allá. Por otra parte, me parece que no todos los filósofos extranjeros que se anuncian como maestros en nuestros salones lo son realmente. Pero este es un asunto que ha de examinarse caso por caso.

${ }^{6}$ No es este el lugar para exponer todas las razones -filosóficas, culturales, políticas- por las cuales es preferible hacer filosofía en nuestra lengua materna que en una extranjera. La mayor parte de ellas son obvias. Lorenzo Peña ha ofrecido buenos argumentos para sostener que el filosofar de una persona es más libre, creador y vigoroso si lo hace en su propia lengua. (Vid. "Filosofar en castellano: vicisitudes y tareas en la perspectiva de la filosofía contemporánea”, en Actas del V Seminario de Historia de la Filosofía Española, Salamanca, 1988.) 
gan muy poco entre ellos, por lo que sus comunidades filosóficas son muy endebles. Un modernizador rara vez lee a otro modernizador, ya que está muy ocupado en leer a los extranjeros. Cuando llega a leer a alguno de sus colegas casi nunca lo cita y cuando lo hace no entabla con él un diálogo constructivo. Pareciera que ocuparse de la obra de un filósofo latinoamericano es, entre los modernizadores, una muestra de la poca ambición o calidad del que lo hace, algo casi de mal gusto, ya que ¿por qué habría uno de citar a un filósofo latinoamericano cuando puede uno citar a uno de otro lado?

La segunda característica compartida de estos movimientos es su espíritu revolucionario. Es decir, han buscado sustituir el viejo orden, por considerarlo caduco y equivocado, por uno nuevo. Nuestras modernizaciones han coincidido en su lucha contra la metafísica tradicional y el ensayismo filosófico, y en su defensa de una concepción de la filosofía como una ciencia rigurosa. Nuestros filósofos encontraron en el positivismo, el marxismo, el neokantismo, la fenomenología y la analítica, métodos de investigación que aspiraban alcanzar los niveles de rigor y precisión de las ciencias. Sin embargo, las coincidencias que había en estos movimientos no se sumaron, sino que se perdieron: el positivismo luchó contra la escolástica, el neokantismo contra el positivismo, la fenomenología contra el neokantismo, el marxismo contra todos los demás y lo mismo sucedió con la analítica. En consecuencia, los resultados de cada modernización casi siempre se perdieron en la siguiente. ${ }^{7}$

La tercera característica en común es que han fracasado en su intento de fundar una nueva tradición filosófica en nuestros países. Ni el positivismo, ni el marxismo, ni la fenomenología, ni el neokantismo lograron encauzar la filosofía latinoamericana como se habían propuesto y lo mismo podría decirse, hasta el momento, de la analítica. Nuestras modernizaciones casi siempre han perdido su ímpetu en el transcurso de una generación, la de sus fundadores, y luego son sustituidas por nuevas modernizaciones. Cada generación de modernizadores ha caído en la tentación de fundar otra vez la filosofía en América Latina. Pero como ya he dicho, el periodo de aprendizaje de las nuevas ideas -que otros describirían como el periodo de mera imitación- se prolonga demasiado y no se logra entablar conexiones profundas y estables con los demás ámbitos de la cultura y la sociedad. Esto es resultado no sólo de

7 Por ejemplo, la primera generación de analíticos mexicanos se formó en el estudio sistemático de las obras fundamentales de la tradición germana. Pero cuando deciden pasarse al bando de la filosofía analítica, se ven obligados a aprender una nueva tradición, la anglosajona, y dejan atrás su formación germana inicial. De modo que la segunda generación de analíticos mexicanos no hereda nada de la formación germana de sus maestros, ni siquiera el aprendizaje del idioma alemán. En consecuencia, una rama prometedora de la filosofía mexicana -y que había costado mucho trabajo plantar- quedó trunca. 
la ausencia de diálogo genuino entre los modernizadores, sino de la pobreza de su memoria. ${ }^{8}$ Se nos podría responder que no estamos obligados a leer a nuestros antepasados filosóficos ya que cuando ellos pretendían ser originales resultaban ser malos filósofos, y nadie está obligado a leer a un mal filósofo. Por otra parte, si tan sólo eran divulgadores de filósofos extranjeros, se nos diría que es preferible leer a dichos filósofos extranjeros de manera directa. Acepto que hay pocas razones para leer a un mal filósofo o a un mero divulgador. Pero no estoy convencido de la verdad a priori de la tesis de que no hay nada que aprender de nuestro pasado filosófico. Para hacer este juicio es preciso leer con atención las obras del pasado y hacer una crítica cuidadosa de ellas. De esta lectura obtendremos elementos que nos permitirán consolidar nuestra filosofía, ya sea rescatando lo que encontremos de valor en ella o descartando, con fundamento, lo que sea preferible olvidar.

Me parece que el modelo modernizador está agotado. No pienso que nuestras modernizaciones fueran desafortunadas o perjudiciales; por el contrario, pienso que fueron necesarias y beneficiosas en el pasado, y que aún tenemos mucho que aprender de ellas. Pero creo que ahora tenemos que tomar otros rumbos.

\section{El modelo de la autenticidad}

Lo que llamo el modelo de la autenticidad ha sido una reacción interna al modelo modernizador, pero también es la expresión filosófica de un movimiento de reafirmación de lo nacional y lo americano que se da en las artes, la literatura y la cultura en general en todos nuestros países desde el primer tercio del siglo XIX. Si el propósito de los defensores del modelo modernizador es estar, como decía Ortega, a la altura de los tiempos y ser así mejores filósofos, el propósito de los defensores del modelo de la autenticidad es que nuestro pensamiento filosófico sea resultado de una profunda reflexión que sea, sobre todo, coherente con nuestra realidad social, cultural y personal.

No se piense que los modernizadores no hayan deseado hacer una filosofía auténtica. Pero para ellos, filosofar auténticamente es, como ha señalado Luis Villoro, filosofar de acuerdo a razones propias, $i$.e . de manera autónoma. ${ }^{9}$ Para

${ }^{8}$ Demos otro ejemplo mexicano. Aunque la historia del kantismo en México tiene casi 150 años, no hay una tradición kantiana mexicana. Esto se debe a que casi todos los kantianos mexicanos de la actualidad ignoran la obra de los neokantianos mexicanos de la primera mitad del siglo $\mathrm{Xx}$, como ellos, a su vez, ignoraron a los que en el siglo XIX adoptaron la filosofia kantiana en su lucha contra el positivismo.

${ }^{9}$ Vid. Luis Villoro, En México, entre libros. México, FCE, 1995, pp. 90-118. 
los defensores del modelo de la autenticidad, filosofar de manera auténtica significa, además de lo anterior, filosofar de manera congruente con motivos propios y, por lo tanto, con nuestra condición personal y social.

Aunque hay varias corrientes que siguen el modelo de la autenticidad -algunas muy distintas a las otras e incluso antagónicas- podemos decir que todas ellas coinciden en algunos puntos.

Uno de ellos es que la filosofía en América Latina debe tener un sello propio sin que por ello, haya de renunciar a una pretensión de universalidad. En este punto, la metafilosofía práctica latinoamericana se ha convertido en una crítica de la filosófica europea, que ha escondido un eurocentrismo y otros "ismos" detrás de su supuesta universalidad. Para algunos, el sello propio de la filosofía latinoamericana ha de surgir de los temas mismos; para otros este carácter emana de la problemática concreta que nos lleva a reflexionar sobre temas universales; mientras que para otros más este sello se obtiene tan sólo con la autenticidad de nuestra reflexión sobre cualquier tema.

Otro punto en común es el de que la filosofía latinoamericana ha de ser una filosofía liberadora. La idea es que para que nuestra filosofía sea auténtica, no sólo debe reflexionar pasivamente acerca de las condiciones de opresión e injusticia que nos imponen desde afuera las potencias coloniales y desde adentro las clases dominantes, sino que debe ser un instrumento más para alcanzar dicha liberación. Pero aquí hay diferencias, mientras que algunos parecen conformarse con que la filosofía latinoamericana sea liberadora de conciencias, otros insisten en que lo sea de nuestra circunstancia concreta, $i . e$. política y económica.

Si en el caso del modelo modernizador hablamos de oleadas de movimientos modernizadores, en el caso del modelo de la autenticidad vamos a hablar de momentos en la conformación de dicho modelo. Voy a señalar un momento mexicano, uno peruano y uno argentino.

El momento mexicano inicia temprano en el siglo Xx. Antonio Caso y Samuel Ramos reflexionaron sobre los problemas del mexicano y de su historia. José Vasconcelos ubicó en América Latina al hombre del futuro. José Gaos promovió el estudio sistemático de la historia de las ideas para cobrar conciencia de las características de lo que ha sido el pensamiento filosófico en América Latina y como una condición para la eventual conformación de una filosofía propia. Leopoldo Zea toma de Gaos la convicción de la importancia del estudio de la historia de las ideas, pero va más allá. En 1942, Zea publicó "En torno a una filosofía americana", ensayo seminal en donde afirmaba que el filósofo latinoamericano debía ocuparse de los problemas propios de su circunstancia. Poco después, en "La filosofía como compromiso", otro texto fundacional, sostuvo que el filósofo latinoamericano tiene, además, una responsabilidad frente a dichos problemas, i. e. tiene que hacer algo para solu- 
cionarlos. En el mediodía del siglo xx, el grupo Hiperión, en donde figuraban Emilio Uranga y Luis Villoro, se propuso hacer una filosofía de lo mexicano. Pero el movimiento fue efímero y sus integrantes volvieron a cultivar el modelo modernizador. Zea y sus discípulos, sin embargo, han continuado en la ruta de la filosofía latinoamericana.

El momento peruano tiene como antecedentes a Manuel González Prada, padre del indigenismo peruano, y a José Carlos Mariátegui, autor de Siete ensayos de interpretación a la realidad peruana. Pero me parece que este momento tiene su actividad más importante en los años sesentas y setentas del siglo XX. En esos años, Francisco Miró Quesada, uno de nuestros más grandes modernizadores, dirige sus intereses a la cuestión sobre la filosofía latinoamericana y publica varios estudios penetrantes sobre la historia y la interpretación de nuestra filosofía de los que más adelante haremos algunos comentarios. Por otra parte, Augusto Salazar Bondy publica en 1968 un pequeño clásico, ¿Existe una filosofía de nuestra América?, en donde responde negativamente a esta pregunta (en contra de lo que Gaos y Zea habían dicho). Salazar Bondy afirma que el problema de nuestra filosofía es la inautenticidad y que ésta se arraiga en nuestra condición de países subdesarrollados y dominados. Para lograr la autenticidad, los filósofos latinoamericanos tienen que cobrar conciencia de su condición de hombres colonizados y esforzarse por cancelarla. Dentro del momento peruano también debe incluirse a Gustavo Gutiérrez, autor de Teología de la liberación, obra pionera de esta corriente teológica.

El momento argentino tiene antecedentes que podrían remontarse a Alberdi. A mediados del siglo xx Francisco Romero y Risieri Frondizi reflexionaron sobre la naturaleza de la filosofía latinoamericana, aunque desde una perspectiva contraria a la de la autenticidad. Pero lo que yo llamo el momento argentino sucede a partir de la década de los setentas, justo después del momento peruano. En 1973 nace el movimiento de la filosofía de la liberación, que siguiendo una línea trazada por Salazar Bondy y por la llamada opción por los pobres adoptada por la teología de la liberación, se propone la creación de una filosofía orientada a la lucha contra la explotación que padecen los pueblos del mundo entero y en especial, los de América Latina. Entre los miembros de este movimiento podemos destacar a Enrique Dussel y Arturo Andrés Roig. El movimiento es reprimido por el gobierno poco después de haberse gestado y varios de sus miembros tienen que salir de Argentina. Por otra parte, pronto surgieron divisiones muy profundas entre ellos. ${ }^{10}$

Quiero dejar muy en claro que cuando hablo de estos momentos del modelo de la autenticidad no quiero decir que sólo se ha practicado en estos tres

${ }^{10}$ Vid. Horacio Cerruti, Filosofía de la liberación latinoamericana. México, FCE, 1992. 
países o que en cada uno de ellos sólo se ha trabajado en él durante estos periodos. El esquema de los tres momentos debe verse como una modelo aproximado y nada más.

El modelo de la autenticidad tiene varias deficiencias. Aquí voy a considerar cinco de ellas.

1. Una de ellas -que creo ha sido corregida- es el error de confundir la peculiaridad de los temas de la filosofía latinoamericana con su autenticidad. Uno puede reflexionar sobre temas latinoamericanos de manera asaz inauténtica. Por otra parte, no es preciso adoptar el modelo de la autenticidad para que reflexionemos filosóficamente sobre cuestiones como la identidad cultural de nuestros pueblos.

2. Un problema, más común, es que algunos defensores del modelo de la autenticidad reinciden subrepticiamente en el modelo modernizador, ya que se apoyan en la autoridad e incluso en la novedad de los autores extranjeros que encuentran más afines a sus propuestas, para atacar a los modernizadores latinoamericanos que enarbolan la bandera de otros autores extranjeros. Me parece que esto explica la percepción dentro del modelo de la autenticidad de que algunas propuestas de filósofos que siguen este modelo han pasado de moda. ${ }^{11}$

3. Otro problema, igualmente grave y actual, es que, si bien algunas de las figuras centrales del modelo de la autenticidad han sido - y son- pensadores de gran cultura y talento filosófico, sus seguidores, es decir, la mayoría de los practicantes del modelo, se han enclaustrado en un espacio bastante estrecho de autores, temas y metodología. Esto ha tenido como consecuencia, en mi opinión, lo que me atrevería a llamar el empobrecimiento filosófico de muchos de los practicantes de este modelo. Los temas se repiten una y otra vez, se glosan las ideas principales de mil maneras distintas y hay una clara deficiencia en el rigor y la claridad.

4. Otro problema, relacionado con lo anterior, es que los defensores del modelo de la autenticidad han tendido al sectarismo. Sólo dialogan entre sí, siempre sobre los mismos temas y rara vez de manera crítica. No se ocupan de la obra de los modernizadores porque consideran que no merece ser estudiada a fondo. A las obras de los modernizadores sólo se les menciona superficialmente para acusarlas de ser inauténticas o incluso de ser ideología de la clase dominante, pero no se toman en cuenta las ideas y los argumentos que hay en ellas.

5. Finalmente, está el supuesto de varios defensores de este modelo de que la causa de todos los problemas de la filosofía latinoamericana es la condi-

${ }^{11}$ Por ejemplo, los defensores del modelo que se basan en Heidegger han considerado que los que todavía se apoyan en el historicismo han sido superados. Pero este es un juicio que, me parece, presupone el modelo modernizador. 
ción de dependencia política y económica de nuestros pueblos y que, por lo tanto, su solución, y la tarea que deben asumir los filósofos latinoamericanos, es la de cambiar tal condición. Además de que este supuesto está basado en una concepción algo limitada de la filosofía, me parece que no hay ninguna garantía de que la ansiada liberación política y económica de nuestros pueblos nos haga filósofos más auténticos o más originales o más competentes. ${ }^{12}$

Pienso que si bien hay grupos establecidos que practican el modelo de la autenticidad en todos nuestros países, el modelo se encuentra actualmente en un periodo de estancamiento. No hay ideas nuevas en este campo desde hace un par de décadas y no se vislumbran figuras más jóvenes que reemplacen a los de mayor edad. Como en el caso del modelo modernizador, creo que el modelo de la autenticidad ya llegó a su límite. Podemos recuperar sus mejores lecciones y con ellas plantear un nuevo modelo para la filosofía en nuestros países.

\section{El problema de la filosofía latinoamericana}

Para los defensores del modelo modernizador el problema de la filosofía latinoamericana ha sido su atraso técnico, temático y profesional. Para los defensores del modelo de la autenticidad el problema de la filosofía latinoamericana ha sido su enajenación, su incongruencia con la realidad, en suma, su inautenticidad. Ambos modelos respondieron a la situación de la filosofía en nuestros países desde mediados del siglo XIX hasta el último cuarto del XX. Pero estos modelos ya no nos sirven. La realidad de nuestra filosofía los ha dejado atrás.

Mi propuesta consiste en superar esta dicotomía. No hay duda de que la filosofia latinoamericana ha padecido y padece de atraso y de inautenticidad. Pero pienso que el verdadero problema de nuestra filosofía es la debilidad, cuando no inexistencia, de comunidades filosóficas y la fragilidad, cuando no ausencia, de tradiciones filosóficas. Y me parece que el origen de este problema es que no hemos querido o podido o sabido dialogar ni hacer memoria -aunque a fin de cuentas, la falta de diálogo es el problema principal, ya que la memoria cultivada en una comunidad filosófica, la memoria que preserva una tradición filosófica, es una especie de diálogo permanente con las figuras de un pasado compartido, es decir, de nuestro pasado. Pienso que ésta es la causa principal de que la filosofía en nuestros países haya tenido

${ }^{12}$ Recordemos que hay países del primer mundo en los que la filosofía padece problemas muy similares a los de la filosofía latinoamericana. Un caso que nos es cercano es el de España. 
poca continuidad, calidad y repercusión interna y externa. No podremos elevar el nivel de nuestra filosofía, ni hacerla una reflexión más auténtica, si no solucionamos antes el problema al que he aludido.

Quiero subrayar que se trata de un problema que requiere soluciones prácticas. No podemos dejar que las cosas sigan como están, ya que nada indica que el problema vaya a resolverse por sí solo. Por lo tanto, pienso que tenemos que proponer acciones concretas dirigidas a la conformación y el fortalecimiento de tradiciones y de comunidades.

Hablemos primero del problema de la ausencia de tradiciones y luego de la precariedad de nuestras comunidades filosóficas. Este orden de exposición es arbitrario. Sin tradición no hay comunidad y viceversa.

A primera vista parecería que el modelo modernizador ha sido el único responsable de que no tengamos tradiciones locales, ya sean éstas doctrinales o nacionales y, por ello, de que no tengamos una tradición latinoamericana o iberoamericana. Pero algunas versiones de la filosofía de la autenticidad han sido más radicales al querer fundar en América Latina una nueva filosofía desde cero, sin tomar en cuenta lo que han hecho los filósofos del pasado de aquí y de allá. En realidad, este problema tiene raíces más profundas que hay que considerar aunque sea rápidamente.

Nuestra tradición filosófica originaria es la escolástica. A partir de la primera mitad del siglo XVII, en todos nuestros países empieza a haber tensiones entre la filosofía moderna y la ilustrada, por un lado, y la escolástica, por el otro, pero es en el siglo XIX cuando nos encontramos con una lucha abierta entre la escolástica y filosofías como el liberalismo, el krausismo y el positivismo. Hacia la segunda mitad del siglo XIX las fuerzas filosóficas (y políticas) contrarias a la escolástica habían triunfado casi en todas partes. ${ }^{13} \mathrm{El}$ problema fue que el abandono de la tradición escolástica dejó a la filosofía latinoamericana en un estado de tabula rasa. Al haberse perdido nuestro pasado filosófico, había que adoptar -o crear- nuevas filosofías sin una base

${ }^{13}$ La pugna entre la escolástica y la filosofía moderna -recordémoslo- tomó bandos políticos irreconciliables. En México la derrota ideológica y política de la escolástica fue definitiva. En otros países la reacción buscó imponer de nuevo la filosofía escolástica como filosofía oficial. Tal fue el caso de España durante la mayor parte del franquismo y, en menor grado, de Argentina durante la dictadura militar. Aunque se sigue cultivando la escolástica en todos los países de América Latina, es un hecho que ésta ha dejado de ser nuestra tradición filosófica y que ya no puede volver a serlo. Sin embargo, considero que debemos conocerla a fondo, no sólo por ser nuestra tradición original sino porque hay en ella, como decía Leibniz, mucha más solidez de la que imaginamos. Un ejemplo de cómo se puede integrar nuestra tradición filosófica original con la filosofía contemporánea de manera fructífera es la obra del filósofo mexicano Mauricio Beuchot. 
previa. Francisco Miró Quesada es quizá quien mejor se ha dado cuenta de los problemas que ha ocasionado a los filósofos latinoamericanos el haber perdido una tradición filosófica original desde la cual pudieran comprender la filosofía europea y crear una propia. ${ }^{14}$ Coincido casi plenamente con el análisis que realiza Miró Quesada de los problemas del filosofar latinoamericano. Sin embargo, creo que Miró Quesada es demasiado optimista por lo que respecta a la solución de dichos problemas. Él pensaba que conocer suficientemente la tradición europea como para poder repensarla por nuestra cuenta basta para crear una filosofía propia. Pero creo que Miró Quesada no se percató de que conocer a fondo la tradición europea y comprender cabalmente las obras más recientes de dicha tradición, no es suficiente para que tengamos una tradición filosófica propia, ni para decir que pertenecemos a una de las tradiciones filosóficas europeas. Los problemas del filósofo latinoamericano no sólo son resultado de que haya tenido que apropiarse de la filosofía europea sin pertenecer a la tradición de la que emana dicha filosofía y que le da sentido, sino también de los hábitos, prejuicios y actitudes del filósofo latinoamericano típico. ${ }^{15}$

Mi propuesta de fortalecer nuestras tradiciones y de crear otras nuevas no debe confundirse con una defensa del tradicionalismo. Para éste la tradición es una sola, inmutable y no se le puede criticar ya que es la depositaria de la verdad última. En contra de esta concepción de la tradición, Ortega decía que había que ir contra ella, más allá de ella. No se trata de volver a la tradición ultramontana y esclerótica. Se trata de consolidar no una, sino, de ser posible, varias tradiciones filosóficas en las que impere un genuino espíritu crítico. Las tradiciones en cuestión pueden estar basadas en una doctrina filosófica o en un conjunto de ellas, en una corriente filosófica o en una síntesis de ellas, o pueden ser tradiciones nacionales, multinacionales, lingüisticas o multilingüísticas.

No puede haber una tradición en donde no hay una memoria de las ideas filosóficas y las discusiones acerca de ellas. En nuestro caso esto rara vez ha sucedido. Cada generación parece querer olvidar lo que hizo la anterior. Pero una tradición filosófica no puede establecerse en el transcurso de una genera-

${ }^{14}$ Miró Quesada describe las tribulaciones de los filósofos latinoamericanos para repensar las obras de los filósofos europeos, i. e., por repensarlas sin estar inmersos, como ellos, en una tradición que les dé sentido. (Vid. Francisco Miró Quesada, $E l$ problema de la filosofía latinoamericana. México, FCE, 1976.)

${ }^{15}$ Carlos Pereda ha descrito con agudeza algunos de estos vicios: el fervor sucursalero, el afán de novedades, el entusiasmo nacionalista. (Vid. Carlos Pereda, Debates. México, FCE, 1987, p. 135.) Sobre esto mismo véase también Eduardo Rabossi, "Filosofar: profesionalismo, profesionalidad, tics y modales", en Cuadernos de Filosofía, núm. 40. Buenos Aires, abril de 1994, p. 87. 
ción. Y, por otra parte, una tradición no puede depender demasiado de la adopción de ciertas doctrinas o tesis, ya que es natural que éstas se modifiquen o incluso se abandonen en el transcurso de las generaciones (pensemos, por ejemplo, en la relación entre el cartesianismo y la tradición filosófica francesa). Una tradición es, como ha dicho Gadamer, el horizonte de comprensión en el que aparecen y perecen las ideas y las doctrinas filosóficas, en donde suceden las luchas entre ellas, en donde se divisan las ideas nuevas. Una tradición es lo que nos permite entrar en contacto con lo nuevo, modernizarnos incluso, sin perder lo que se ha recorrido hasta el momento, asimilándolo a lo ya existente. Cambiar preservando y preservar cambiando es la divisa de una tradición viva. Nosotros, por el contrario, nos hemos vistos obligados a abandonar para modernizar, a dejar todo lo viejo como si fuera un lastre. Es como si para cambiar el mobiliario de una casa, tuviéramos que mudarnos a otra nueva.

Consideremos ahora la cuestión de las comunidades filosóficas.

Una comunidad filosófica no debe confundirse con un conjunto de filósofos que viven en un mismo país, región o que trabajan sobre temas afines o con una metodología similar o que son miembros de una misma asociación o de una misma Facultad o que tienen las mismas influencias y los mismos intereses o que publican en las mismas revistas o editoriales. Una comunidad filosófica verdadera es un conjunto de filósofos que además de compartir algunos o todos los elementos anteriores, entablan un diálogo o varios de ellos. Para que estos diálogos sean fructíferos han de girar alrededor de temas y problemas comunes que constituyan un marco de referencia compartido. Estos diálogos también han de ser rigurosamente críticos, no de las personas -este es un error del que, aparentemente, no hemos podido todavía librarnos- sino de las ideas defendidas por esas personas. Sin crítica genuina es difícil que haya algún avance firme en la comprensión de los problemas, ya que los avances logrados serán todos personales y no colectivos. Y sin un diálogo crítico el destino de los logros personales es la tumba de los libros y las revistas que nadie abre, nadie lee y nadie recuerda. La crítica es la mejor manera para subrayar los elementos positivos de un discurso. Sin crítica, lo bueno, lo regular y lo malo quedan a un mismo nivel.

Si bien en nuestros países existen comunidades filosóficas, éstas son más bien pequeñas y están congregadas, casi siempre, en una institución académica o en una sociedad filosófica. De este modo, tenemos la comunidad filosófica de la universidad $x$ o la de la sociedad de fenomenólogos $z$. No pocas de estas comunidades editan una revista propia y organizan encuentros académicos sobre temas de su interés. Sin embargo, estas comunidades casi siempre giran alrededor de ciertos intereses o afiliaciones comunes, en vez de que lo hagan alrededor de una discusión crítica entre sus miembros. Por otra parte, 
tampoco existe un diálogo entre las diversas comunidades, por lo que no tenemos comunidades nacionales sólidas. Esto puede observarse con la lectura de casi cualquier artículo o libro publicado en nuestros países. Casi nunca se discute en ellos lo que han escrito otros filósofos del mismo país sobre el mismo tema. ${ }^{16} \mathrm{El}$ resultado de esto es que los libros y las revistas que tanto nos esmeramos en publicar se van acumulando en los rincones de nuestras librerías y bibliotecas sin ser leídos o recordados. Este es el triste destino de la mayoría de nuestras obras, incluso de las mejores. Todos lo sabemos, pero actuamos como si no sucediera. Pero soy optimista. Hay signos alentadores de que los filósofos latinoamericanos, especialmente los de generaciones recientes, buscan entablar diálogos genuinos entre sí -dentro de los congresos y fuera de ellos- haciendo a un lado las viejas barreras geográficas, ideológicas y personales que han dividido a los miembros de generaciones anteriores. ${ }^{17}$

\section{Más allá de la modernización y de la autenticidad}

He afirmado que el problema principal de la filosofía latinoamericana es que carecemos de comunidades y tradiciones filosóficas, y que no podremos tener-

16 Esto puede constatarse en la Enciclopedia Filosófica Iberoamericana. Si uno examina la bibliografía de la mayoría de los artículos de esta enciclopedia, advertirá que casi nunca se citan trabajos de filósofos iberoamericanos. Por lo que no podemos decir que esta enciclopedia sea el producto de una genuina comunidad filosófica iberoamericana o que su publicación sirva para la consolidación de dicha comunidad. Y lo mismo puede decirse de casi todos nuestros congresos. Un conjunto de filósofos que se reúnen durante unos pocos días para leer ponencias no constituye una verdadera comunidad filosófica. Suponer que con un solo congreso puede expedirse el acta de nacimiento de una comunidad filosófica -como han afirmado algunos de los organizadores del I Congreso Iberoamericano de Filosofía- es pecar de optimismo. De poco sirven los congresos y las enciclopedias si no generan y alimentan discusiones críticas permanentes.

${ }^{17}$ La exhortación para que dialoguemos entre nosotros no debe verse como un rechazo o una falta de interés por entablar diálogos con las comunidades centrales de la filosofía mundial. Por el contrario, pienso que el diálogo entre nosotros y ellos será más rico y más interesante para ambas partes cuando tenga como base los temas y las propuestas que hayan surgido de un diálogo previo entre nosotros. De otro modo, poco interés hay en los extranjeros por dialogar con nosotros, cuando lo que les decimos es una glosa de lo que ellos dicen en sus propias comunidades. Por otra parte, si lo que se busca es privilegiar el diálogo con ellos a toda costa, la alternativa que queda -tomada por algunos de nuestros filósofos analíticos e incluso fomentada en algunos sectores de dicha comunidad- es la inserción plena a otra comunidad. Pero si bien ésta es una opción personal legítima, no puede ser un proyecto de filosofía latinoamericana, ya que implica la desconexión definitiva entre la labor filosófica y el entorno cultural y social, el abandono del idioma español y, a fin de cuentas, la emigración a otros países. 
las a menos que entablemos un diálogo crítico genuino entre nosotros y ejercitemos, a la vez, una memoria constante y renovadora de diálogos pasados.

El modelo que he propuesto para comprender y solucionar el problema de la filosofía latinoamericana podría recibir el nombre de modelo dialógico. En este trabajo me he ocupado de esbozar el aspecto más práctico de la metafilosofía que sustenta este modelo. La parte teórica tendría que reflexionar sobre la naturaleza dialógica y comunitaria del filosofar. De estos asuntos más teóricos, más generales, me ocuparé en otra ocasión.

Volvamos al problema de la filosofía latinoamericana. ¿Cómo podríamos solucionarlo? ¿Qué podemos hacer para propiciar el diálogo y la memoria entre nosotros?

Voy a proponer unas cuantas vías de acción muy generales. Seguramente hay otras. Ésta es una labor que requiere de la participación de todos los filósofos latinoamericanos. Pero sobre todo, de la convicción compartida de que hay que hacer algo. En especial, de la voluntad de dialogar. El problema no va resolverse desde la oficina del director de una facultad o del consejo de redacción de una revista. Sin embargo, hay medidas que pueden tomarse en el ámbito institucional para estimular la generación de condiciones más propicias para el diálogo y la memoria. Los programas de estudio de nuestras facultades de filosofía tendrían que buscar nuevas maneras para inculcar en nuestros alumnos el hábito del diálogo crítico a la vez respetuoso, del diálogo riguroso a la vez que imaginativo. También debería cambiar la manera en la que estudiamos la historia de nuestra filosofía, habría que tomar nuestro pasado como algo que nos permita entender mejor nuestro presente, pero también como algo que nos permita comprender lo nuevo, venga de fuera o de dentro. Todo esto sin glorificar nuestro pasado de manera acrítica o chabacana, y sin cerrar las ventanas hacia otras comunidades y tradiciones. Por otra parte, hay mucho que hacer en nuestras revistas y demás proyectos editoriales. Habría que fomentar más los debates y las reseñas de fondo. También convendría estimular los estudios sobre nuestra historia filosófica, en particular sobre las relaciones, semejanzas y desemejanzas que hay entre las filosofias de nuestros países y entre las diversas corrientes filosóficas que hemos cultivado en ellos. Esto y más puede hacerse, pero como dije antes, lo importante es que cambien las actitudes y prejuicios de los filósofos latinoamericanos.

Estos cambios no deben sepultar los logros de los modernizadores y de los defensores de la autenticidad. Por el contrario, es preciso rescatar lo mejor de ambos modelos para poder llevar a cabo lo que propongo. También convendría hacer lo mismo con otros modelos, ahora menos protagónicos, del filosofar latinoamericano. Uno de ellos, del que ya he hablado, es la escolástica. Otro, no menos importante y quizá más vital, es el del cultivo del ensayo filosófico más cercano a la pieza literaria que al informe científico. En contra de este 
modelo ensayista se han dado argumentos desde todos los bandos. Son bien conocidos y no los repetiré aquí. Pero pienso que tendríamos mucho que ganar si en vez de ver este modelo con tanta desconfianza, nos preocupáramos por cultivarlo con rigor e imaginación. En países como los nuestros, en donde las artes y las letras son, por lo general, de mejor nivel que las ciencias, es difícil comprender por qué no se fomenta más la relación entre ambas esferas. Lo que no significa, por supuesto, que no debamos seguir propiciando el contacto -todavía muy escaso- entre los filósofos y los científicos en nuestros países.

Pero volvamos -ya para acabar- a lo que debe rescatarse del modelo modernizador y del de la autenticidad.

De los modernizadores recobremos su vigorosa defensa del rigor y el profesionalismo, su actitud abierta a lo nuevo, venga de donde venga, su afán de estar al tanto. No se trata de abandonar el modelo modernizador para practicar una filosofía ensimismada o pueblerina. Se trata de construir una tradición propia que permita que el efecto de las modernizaciones sea profundo y en verdad permanente, que nos permita entablar un diálogo genuino con otras tradiciones y que, al mismo tiempo, entre en contacto fértil con otros elementos de nuestra cultura y nuestra historia.

Del modelo de la autenticidad rescatemos su defensa de la autonomía, su insistencia en la necesidad de que haya congruencia entre nuestro pensamiento y nuestra realidad y, sobre todo, su defensa de la libertad. Todos estos ideales han de rescatarse. Pero debemos entender que para que una filosofía sea liberadora debe convertirse en un afluente de la tradición de la comunidad intelectual a la que pertenecen los hombres y mujeres que se desea liberar. De otro modo, la filosofía que pretende ser liberadora se convierte en aquello que ella repudia, a saber, en un feudo académico más, en algo que se discute sólo en unos cuantos salones mal iluminados de nuestras universidades o en unas cuantas revistas de escasa circulación e impacto.

Para que tengamos la filosofía latinoamericana que queremos es preciso construir con paciencia y perseverancia, entusiasmo y disciplina, comunidades y tradiciones filosóficas propias. 